\title{
Changes in Extracellular Dopamine Induced by Morphine and Cocaine: Crucial Control by D2 Receptors
}

\author{
Françoise Rougé-Pont, ${ }^{1 *}$ Alessandro Usiello, ${ }^{3 *}$ Marianne Benoit-Marand, ${ }^{2 *}$ François Gonon, ${ }^{2}$ \\ Pier Vincenzo Piazza, ${ }^{1}$ and Emiliana Borrelli ${ }^{3}$ \\ 1 Institut National de la Santé et de la Recherche Médicale (INSERM) U259, Université Victor Segalen Bordeaux 2, 33077 \\ Bordeaux Cedex, France, ${ }^{2}$ Centre National de la Recherche Scientifique (CNRS) Unité Mixte de Recherche 5541, \\ Université V. Segalen Bordeaux 2, 33076 Bordeaux, France, and 3/nstitut de Génétique et de Biologie Moléculaire et \\ Cellulaire, INSERM, CNRS, Université Louis Pasteur, 67404 Illkirch Cedex, Communauté Urbaine de Strasbourg, France
}

An increase of extracellular dopamine (DA) concentration is a major neurobiological substrate of the addictive properties of drugs of abuse. In this article we investigated the contribution of the DA D2 receptor (D2R) in the control of this response. Extracellular DA levels were measured in the striatum of mice lacking D2R expression (D2R-/-) by in vivo microdialysis after administration of the psychostimulant cocaine and the opioid morphine. Interestingly, the increase in extracellular DA induced by both drugs was strikingly higher in D2R-/- than in wildtype littermates. This indicates that D2Rs play a key role in the modulation of DA release in response to drugs of abuse. Furthermore, this observation prompted us to investigate the dopaminergic autoreceptor function in the absence of D2 receptor in D2R-/- mice. Results obtained using complementary mi-

Dopaminergic (DAergic) pathways regulate diverse physiological functions ranging from locomotion to motivated behaviors and pituitary hormone release (Jackson and Westlind-Danielsson, 1994). An altered DAergic neurotransmission seems implicated in several neuropathologies, such as Parkinson's disease and schizophrenia (Seeman and Kapur, 2000). The relevance of a controlled dopamine (DA) release is highlighted by the physiological consequences of the intake of addictive drugs. Practically, all drugs of abuse share the common feature of increasing extracellular concentration of DA in the striatal complex (Di Chiara, 1995; Berke and Hyman, 2000). Individuals with higher predisposition to develop addiction show a higher drug-induced DA release (Piazza and Le Moal, 1996, 1998). Suppression or reduction of drug-induced DA release profoundly decreases the reinforcing effects of drugs (Wise, 1996). Therefore, the molecular identification of the factors modulating the increase in extracellular DA induced by drugs of abuse is a fundamental step in the understanding of the pathophysiological basis of addiction.

At least two types of proteins participate in the regulation of

Received Nov. 15, 2001; revised Feb. 7, 2002; accepted Feb. 8, 2002.

This work was supported by grants from Institut National de la Santé et de la Recherche Médicale (INSERM), Centre National de la Recherche Scientifique, Hopitaux Universitaires de Strasbourg, Mission Interministérielle à la Lutte contre la Drogue et la Toxicomanie, and Association pour la Recherche sue le Cancer (E.B.), INSERM and Université de Bordeaux II (P.V.P.), and the Mariano Scippacercola Foundation and FRM fellowships (A.U.). We are grateful to V. Heidt, Muriel Petit, and Nelly Charrier for technical help.

*F.R.P., A.U., and M.B.M. have equally contributed to this work.

Correspondence should be addressed to E. Borrelli, IGBMC, BP163, 67404 Illkirch Cedex C. U. de Strasbourg, France. E-mail: eb@igbmc.u-strasbg.fr.

Copyright $\odot 2002$ Society for Neuroscience $0270-6474 / 02 / 223293-09 \$ 15.00 / 0$ crodialysis and voltammetry analyses show that the autoreceptor function regulating DA release is totally abolished in the absence of D2R, despite unchanged DA uptake and basal DA efflux. Finally, we propose that the short isoform D2S receptor of the D2 receptors is the one controlling change in DA release induced by drugs of abuse. Indeed, the neurochemical effects of cocaine and morphine are unchanged in animals with a selective deletion of the long isoform D2L receptor. Thus, deregulated expression of $\mathrm{D} 2 \mathrm{R}$ isoforms might be involved in the vulnerability of an individual to drug abuse.

Key words: dopamine; D2 receptors; knock-out mice; dopaminergic autoreceptors; microdialysis; voltammetry; addictive drugs

the extracellular concentration of DA induced by drugs of abuse. The DA transporter (DAT), which re-uptakes DA from the synaptic cleft into DAergic neurons (Graefe and Bonish, 1988; Giros et al., 1996) and the DA autoreceptors. DA autoreceptors once activated by extracellular DA inhibit the firing of DA neurons, as well as DA synthesis and release (Roth, 1984; Starke et al., 1989). DA D2 and D3 receptors (D2R, D3R) have been postulated to have autoreceptor functions (Jackson and Westlind-Danielsson, 1994; Shafer and Levant, 1998). Although it has been possible to define the implication of the DAT in drug abuse by analyzing DAT-/- mice (Giros et al., 1996; Sora et al., 1998), the role of the autoreceptors has been postulated (White and Kalivas, 1998).

In this report we have analyzed the role played by DA D2 autoreceptors in response to systemic administration of the psychostimulant cocaine and the opioid morphine. In vivo microdialysis was used to assess variations in the extracellular concentrations of DA, elicited by these drugs. Experiments were performed using DA D2R mutants in comparison to wild-type (WT) littermates. Two different D2R mutant mice were compared, those lacking both isoforms of the receptor (D2L and D2S) (Baik et al., 1995) and D2L-/- mice (Usiello et al., 2000) in which only the expression of the long isoform is missing. These studies indicate that the D2 receptors directly and firmly regulate the increase in extracellular DA concentrations elicited by morphine and cocaine. We also show, using microdialysis and voltammetry, that deletion of the D2R is a sufficient condition to totally suppress autoreceptor-mediated inhibition of DA release both in the striatum and in the shell of the nucleus accumbens 
(AcbSh). These results suggest that among the D2-like receptor family, the expression of the D2 receptor is a necessary condition to ensure a functional autoreceptor mediated regulation of this function. Finally, parallel analyses performed on D2L knock-out (KO) mice, in which only the D2S isoform of the D2R is expressed, suggest that the D2L receptor does not control the increase in extracellular DA induced by cocaine and morphine. The latest results suggest that the D2S receptor is the DA autoreceptor involved in the control of DA levels after administration of addictive drugs.

\section{MATERIALS AND METHODS}

\section{Animals}

Animals were bred and raised under standard animal housing conditions, in a $12 \mathrm{hr}$ light/dark cycle (lights on between 8:00 A.M. and 8:00 P.M.). Food and water were available ad libitum. D2R-/- (Baik et al., 1995) and D2L-/- mice (Usiello et al., 2000) and the respective WT littermates were used. All mice were in a mixed genetic background (25\% $129 / \mathrm{Sv}$ and $75 \% \mathrm{C} 57 \mathrm{BL} / 6 \mathrm{~J})$ All the experiments were performed in accordance with French (Ministère de l'Agriculture et de la Forêt, 87-848) and European Economic Community (EEC, 86-6091) guidelines for care of laboratory animals.

\section{Drugs}

Cocaine (20 and $40 \mathrm{mg} / \mathrm{kg})$, quinpirole $(0.3 \mathrm{mg} / \mathrm{kg})$, and haloperidol $(0.5$ $\mathrm{mg} / \mathrm{kg}$ ) were injected intraperitoneally; morphine sulfate $(9,18 \mathrm{mg} / \mathrm{kg})$ was injected subcutaneously. Urethane was dissolved in distilled water and injected intraperitoneally.

For microdialysis, all drugs were injected after three stable baseline points ( $<10 \%$ variation) were observed. Drugs concentration for cocaine and morphine were in the range of those inducing unambiguous behavioral effects. For quinpirole and haloperidol the dose used are among the most used for the neurochemical characterization of the presynaptic effect of these drugs.

\section{Microdialysis}

The microdialysis procedure used has been previously described (RougePont et al., 1993). Briefly, anesthetized mice (chloral hydrate; $400 \mathrm{mg} / \mathrm{kg}$, i.p.) were implanted with a guide cannula (CMA-Carnegie MedicinSweden) in the striatum. Damage to the target site was minimized by implanting the tips of the guide cannula $2 \mathrm{~mm}$ above the desired site. The coordinates (in $\mathrm{mm}$ ), were: anteroposterior, +1 ; mediolateral, 1.9; and dorsoventral, -2.5 relative to bregma according to the atlas of Franklin and Paxinos (1997). Dialysis experiments were conducted in freely moving mice. Seven days after surgery, the microdialysis probe (CMA/11; 2 $\mathrm{mm}$ cuprophane membrane length) was inserted through the guide cannula, and the animals returned to their home cage. Animals were transferred to the microdialysis test cage (Phymep, Paris, France) $24 \mathrm{hr}$ after probe implantation. Probes were then connected to a syringe pump (Harvard 22; Harvard Apparatus, South Natick, MA) and perfused at a perfusion rate of $1 \mu \mathrm{l} / \mathrm{min}$ with a modified artificial CSF containing (in mM): $\mathrm{NaCl}, 145 ; \mathrm{KCl}, 2.7 ; \mathrm{CaCl}_{2}, 1.2 ; \mathrm{MgCl}_{2}, 1 ; \mathrm{Na}_{2} \mathrm{HPO}_{4} / \mathrm{NaH}_{2} \mathrm{PO}_{4}$ (buffer), 2, pH 7.4. Microdialysis samples $(20 \mu \mathrm{l})$ were automatically injected in the HPLC every 20 min using a fully automated on-line system. HPLC coupled to a coulometric detector (Coulochem II; ESA, Bedford, MA) was used to detect DA (detection limit: $0.3 \mathrm{pg} / 20 \mu \mathrm{l}$ sample). Cannula placements were verified histologically on $30 \mu \mathrm{m}$ coronal sections using thionine staining. Data were expressed as percentage of baseline. Baseline was defined as the average of the last three preinjection values. At the end of each experiment animals were killed and the brain was removed, frozen at $-20^{\circ} \mathrm{C}$, and cryostat-sectioned into $30-\mu \mathrm{m}$-thick sections collected on gelatin-coated slides. Sections were colored with toluidine blue for anatomical observations. Only animals with corrected placed probes (Fig. 1) were used in data analysis.

\section{In vivo voltammetry}

MFB electrical stimulation. Adult mice were anesthetized with urethane $(1.8 \mathrm{gm} / \mathrm{kg}$, i.p. $)$, fixed in a stereotaxic frame using a mouse adapter (Stoelting Co., Wood Dale, IL), positioned according to the atlas of Franklin and Paxinos (1997), and maintained at $37^{\circ} \mathrm{C}$. In each animal a concentric bipolar stimulating electrode (SNEX-200; Rhodes Medical Instruments) was implanted in the medial forebrain bundle (MFB) 2.1

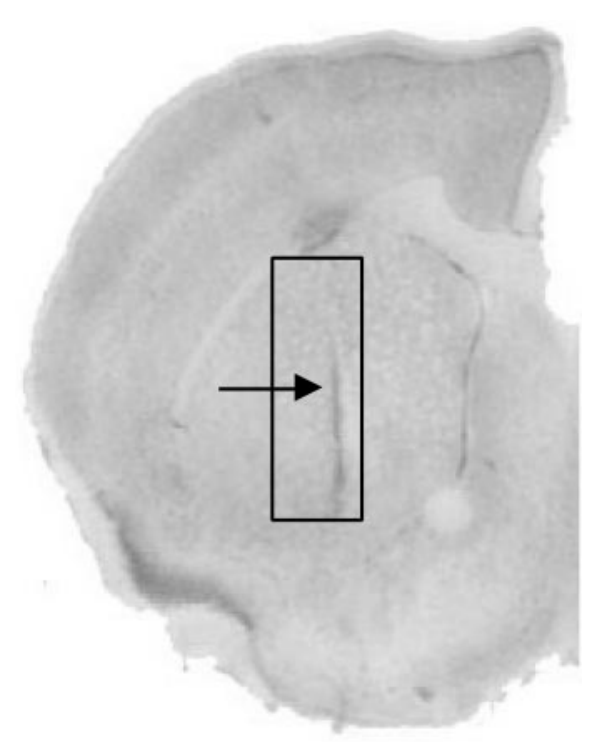

\section{Microdialysis probe: $2 \mathrm{~mm}$ long}

Figure 1. Position of the microdialysis probe in the dorsal striatum. Coronal section $(30 \mu \mathrm{m})$ of a mouse brain showing the implantation site of a dialysis probe, in the dorsal striatum (arrow), and the area within which all probes were contained (rectangle).

$\mathrm{mm}$ posterior to bregma and either 1.1 or $0.8 \mathrm{~mm}$ lateral to medial line to evoke DA release in the striatum or in the AcbSh, respectively. The depth of the stimulating electrode was adjusted for each experiment so that the DA response was maximal. Stimulation pulses $(0.5 \mathrm{msec}, 300$ $\mu \mathrm{A})$ were applied using an isolated stimulator (DS2; Digitimer, Hertfordshire, UK) triggered by a MacLab/2e system (ADInstrument, Castle Hill, New South Wales, Australia).

Electrochemical techniques. The electrochemical technique used here, continuous amperometry with untreated carbon fiber electrodes, provides excellent time resolution and sensitivity. Unfortunately, this technique exhibits a poor chemical resolution as compared with fast scan cyclic voltammetry and can be only used to monitor DA overflow evoked by brief MFB electrical stimulations (Dugast et al., 1994; Michael and Wightman, 1999). However, with respect to brief DA overflow in anesthetized rodents, the validity of this approach has been confirmed by anatomical, pharmacological and physiological data (Dugast et al., 1994; Suaud-Chagny et al., 1995; Benoit-Marand et al., 2000). Moreover, results obtained with this technique are in excellent agreement with similar observations provided by fast scan cyclic voltammetry (Garris and Wightman, 1994; Michael and Wightman, 1999).

Measuring electrodes, whose active surface was a carbon fiber $8 \mu \mathrm{m}$ in diameter and 250- $\mu \mathrm{m}$-long (AGT 10000; SOFICAR, Saint Maurice, France), were implanted either in striatum $(1.7 \mathrm{~mm}$ lateral to medial line, $1.1 \mathrm{~mm}$ anterior to bregma, and $2.75-3.25 \mathrm{~mm}$ below the cortical surface) or in AcbSh (0.6 mm lateral, $1.1 \mathrm{~mm}$ anterior to bregma, and $4.25-4.75$ $\mathrm{mm}$ below the cortical surface). The dura mater was punctured by a used carbon fiber electrode, and the new electrode was lowered through this hole. The reference electrode was a silver wire coated with $\mathrm{AgCl}$ and was maintained in contact with the skull by a sponge moistened with a $0.9 \%$ $\mathrm{NaCl}$ solution. A two electrode potentiostat (AMU 130; Radiometer Analytical, Villeurbanne, France) was used to apply $+0.4 \mathrm{~V}$ to the carbon fiber electrode versus the reference electrode and to record the current passing through them. The amplified signal was digitized by a MacLab/2e system coupled to a Macintosh computer running the "Scope" program (ADInstruments). Train pulses stimulations consisting of four pulses at $100 \mathrm{~Hz}$ (see Fig. 6) or of 10 pulses at $15 \mathrm{~Hz}$ (see Fig. 4) and the sequence of three train stimulations shown in Figure 5 were applied every $15 \mathrm{sec}$. Ten consecutive responses to these stimulations were recorded and averaged on-line. Only averaged responses were stored for subsequent analysis. Time intervals between consecutive train pulse stimulations 
were chosen after preliminary experiments so that consecutive individual evoked responses were stable in terms of kinetics and amplitude. For each type of stimulation the current was also recorded while the carbon fiber electrode was held at $0 \mathrm{~V}$. Because at this potential DA was not oxidized, only transient electrical artifacts caused by the stimulation were recorded (Dugast et al., 1994). To improve the recording of oxidation currents, these artifacts were removed by subtracting data obtained at 0 $\mathrm{V}$ from those recorded at $+0.4 \mathrm{~V}$.

In the dorsal striatum variations in the oxidation current were estimated in terms of changes in DA extracellular concentration on the basis of in vitro calibration of the carbon fiber electrode performed after in vivo measurement as described (Dugast et al., 1994). To perform this measure it was impossible to verify the exact location of the electrode tip in this structure. Indeed, the exact location of the electrode tip can be visualized only inducing an electrolytic lesion that damages the carbon fiber electrode. To ensure a correct placement of the electrode, the exact position of the tip was verified by performing an electrolytic lesion $(+5 \mathrm{~V}$ for 4 $\mathrm{sec}$ ) in three animals before the start of the actual experiments and then in two animals at the end of the experiments. All the tip placements verified this way were in the area of the dorsal striatum shown in Figure $4 D$. Animals used to verify the tip position were not used for data analysis. This strategy was possible because the striatum is a large and relatively homogenous structure. However, in the case of the nucleus AcbSh that is a much smaller brain area the anatomical location of the recording electrode was checked after each experiment by inducing an electrolytic lesion as described above. Because this manipulation forbids the in vitro calibration of the electrode, DA overflow evoked in AcbSh was expressed in picoamperes. Animals in which the recording site was not localized in AcbSh close to islands of Calleja were discarded.

For all the histological verifications the brain was removed, frozen at $-20^{\circ} \mathrm{C}$, and cryostat sectioned into $15-\mu \mathrm{m}$-thick sections collected on gelatin-coated slides. Sections were colored with toluidine blue for anatomical observations.

Data analysis. Two parameters were measured from evoked overflow using the "Scope" software. The maximal amplitude of the overflow was expressed in changes in DA concentration. The DA half-life corresponded to the time to $50 \%$ decay from the point where the maximal overflow was reached. In the experiment described in Figure 5, autoreceptors were activated by DA whose release was evoked by a conditioning stimulation $(\mathrm{Sc})$ consisting of four pulses at $15 \mathrm{~Hz}$. Test stimulations S1 and $\mathrm{S} 2$ consisted of three pulses at $100 \mathrm{~Hz}$ and were respectively applied $4 \mathrm{sec}$ before $\mathrm{Sc}$ and $300 \mathrm{msec}$ after the end of Sc. The amplitude of the DA overflow evoked by $\mathrm{S} 2$ was expressed as a percentage of the overflow evoked by $\mathrm{S} 1$ and was used to measure the inhibition of DA release induced by Sc. Because DA clearance is slower in AcbSh than in striatum, the recording of DA overflow evoked by S2 in AcbSh overlapped with that evoked by Sc. To accurately measure from averaged recordings the amplitude of the overflow evoked by S2, the curve corresponding to a similar overflow evoked by Sc, but not followed by S2 and obtained in the same experiment, was subtracted.

\section{Statistical analysis}

All data were analyzed using ANOVA followed by appropriate post hoc comparisons. Analyses were performed on raw data. For microdialysis, genotype and treatment were used as between-factors and time as withinfactor. For in vivo voltammetry, genotype was used as between-factor and time or treatment as within-factors (haloperidol effect, autoinhibition induced by $\mathrm{Sc}$ ).

\section{RESULTS}

\section{The DAergic response to cocaine and morphine are controlled by $\mathrm{D} 2$ receptors}

$\mathrm{D} 2 \mathrm{R}-/-$ mice represent a useful model to assess the role of $\mathrm{D} 2 \mathrm{R}$ in the control of DA release in the striatum after drug challenge. These mice lack the expression of both the isoforms (D2L and D2S) of the D2R (Baik et al., 1995). Cocaine and morphine effects on the extracellular DA levels were analyzed in WT and D2R $-/-$ mice. Cocaine acts directly on DAergic neurons by blocking the activity of DAT. Morphine, conversely has an indirect effect and evokes DA release by relieving the inhibition of mesencephalic GABAergic interneurons on DAergic cells.

Changes in the extracellular level of DA were evaluated in the striatum (Fig. 1) in freely moving mice of both genotypes by means of microdialysis. The mean baseline concentration (in picograms per $20 \mathrm{~min} \pm \mathrm{SEM}$ ) of DA in striatal dialysates was similar (ANOVA group effect, $F_{(1,69)}=0.32 ; p>0.57$ ) in WT $(5.12 \pm 0.42 ; n=32)$ and $\mathrm{D} 2 \mathrm{R}-/-(5.58 \pm 0.65 ; n=39)$ mice.

Cocaine administration induced a dose- and time-dependent $\left(\right.$ dose $\times$ time interaction, $\left.F_{(10,125)}=3.39 ; p<0.001\right)$ increase in striatal DA in animals of both genotypes (Fig. $2 A$ ). However, this increase was dramatically higher in D2R $-/-$ mutants as compared with WT animals (genotype $\times$ time interaction, $F_{(5,125)}=$ 3.97; $p<0.002$ ). The higher concentration of extracellular DA in D2R-null mice was observed for both cocaine doses $\left(F_{(5,90)}=\right.$ 4.88; $p=0.0006$ ) (Fig. $2 A$ ), but the two groups did not differ in response to saline $\left(F_{(5,35)}=1.37 ; p>0.25\right)$. Interestingly, the response of D2R $-/-$ mice to $20 \mathrm{mg} / \mathrm{kg}$ of cocaine almost doubled that of WT mice at $40 \mathrm{mg} / \mathrm{kg}$. Accordingly, the response of mutant mice to $40 \mathrm{mg} / \mathrm{kg}$ was particularly impressive and to our knowledge well above the range of increases normally observed in WT animals.

We then assessed DA release elicited by morphine in animals of both genotypes (Fig. 2B). Similar to what has been observed in
A

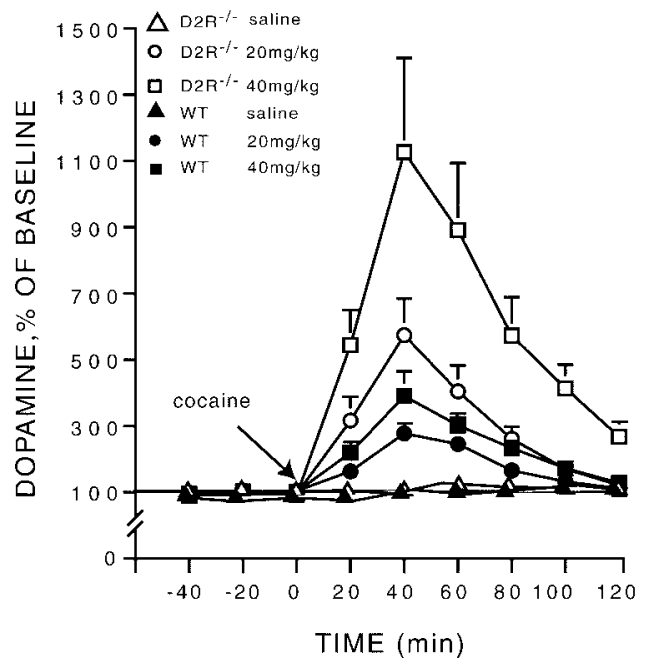

B

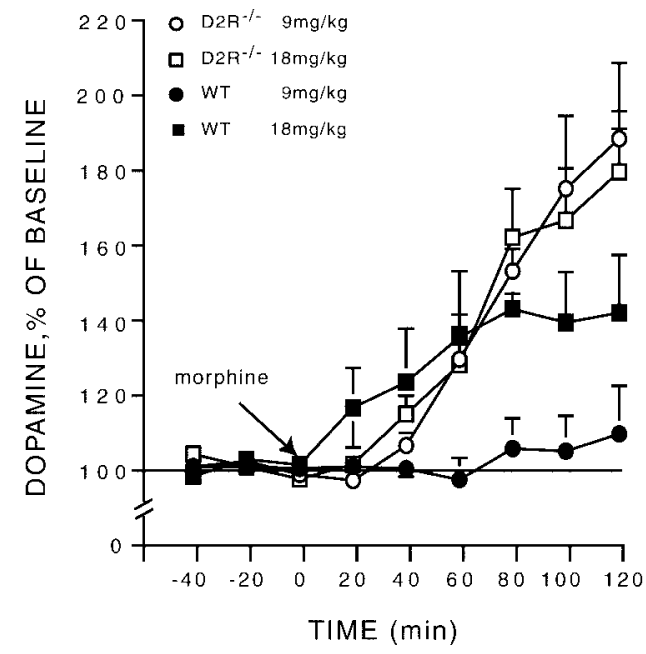

Figure 2. Cocaine- and morphineinduced changes in extracellular concentration of dopamine in WT and $\mathrm{D} 2 \mathrm{R}-/-$ mice. $A$, The administration of cocaine $(20$ and $40 \mathrm{mg} / \mathrm{kg}$, i.p) induced a higher increase in dopamine in $\mathrm{D} 2 \mathrm{R}-/-$ than in WT animals. $B$, The administration of morphine ( 9 and 18 $\mathrm{mg} / \mathrm{kg}$, s.c.) induced a higher increase in dopamine in $\mathrm{D} 2 \mathrm{R}-/-$ than in WT mice. Dialysates were collected in the striatum of freely moving animals every $20 \mathrm{~min}$, and data are expressed as mean \pm SEM of changes from baseline. 
response to cocaine, morphine also drastically increased extracellular DA levels in D2R - /- mice in comparison with WT siblings (genotype $\times$ time interaction, $F_{(5,110)}=9.13 ; p<0.0001$ ) (Fig. $2 B)$. Strikingly, although administration of morphine at $9 \mathrm{mg} / \mathrm{kg}$ failed to induce a significant elevation of DA levels in WT animals $\left(F_{(8,32)}=0.33 ; p>0.27\right)$, it induced a maximal response in mutant mice (Fig. $2 B$ ). Indeed, morphine at $9 \mathrm{mg} / \mathrm{kg}\left(F_{(8,48)}=\right.$ $10.23 ; p<0.0001)$ and $18 \mathrm{mg} / \mathrm{kg}\left(F_{(8,48)}=10.97 ; p<0.0001\right)$ elicited a similar increase of DA extracellular levels in D2R-/mice $\left(F_{(1,12)}=0.23 ; p>0.63\right)$. In contrast, in WT mice a significant effect of morphine on DA release was only observed at $18 \mathrm{mg} / \mathrm{kg}\left(F_{(8,48)}=3.58 ; p<0.003\right)$. However, even at this dose, the increase of DA levels in WT was half that induced in $\mathrm{D} 2 \mathrm{R}-/-$ mice by $9 \mathrm{mg} / \mathrm{kg}$ of morphine.

\section{Haloperidol and quinpirole effects on DA release are suppressed in D2R null mice}

The striking effects of drug-induced changes in extracellular DA level in D2R-/- mice prompted us to analyze to which extent D2R participates to the DAergic autoreceptor functions. Indeed, although it is well established that the DA autoreceptor belongs to the D2-like family (comprising D2, D3, and D4 receptors), the respective role played by each one of these receptors in this function is still controversial. In particular, D2 receptors and D3 receptors have been supposed to serve autoreceptor functions because of their localization on mesencephalic DAergic neurons (Jackson and Westlind-Danielsson, 1994; Diaz et al., 2000).

To investigate the role played by $\mathrm{D} 2 \mathrm{R}$ in mediating autoreceptor functions, the effect on DA release of systemic injections of a D2-like specific receptor antagonist (haloperidol) and agonist (quinpirole) were analyzed. Haloperidol and quinpirole are known to respectively increase and decrease DA release by acting on DA autoreceptors. As expected, in vivo microdialysis in WT mice showed that haloperidol $(0.5 \mathrm{mg} / \mathrm{kg})$ significantly increased $\left(F_{(8,24)}=17.69 ; p<0.0001\right)$ extracellular DA levels, whereas quinpirole $(0.3 \mathrm{mg} / \mathrm{kg})$ significantly decreased it $\left(F_{(8,48)}=56.28\right.$; $p<0.0001)$. In contrast neither haloperidol $\left(F_{(8,32)}=0.66 ; p>\right.$ $0.71)$ nor quinpirole $\left(F_{(8,48)}=0.97 ; p>0.46\right)$ exerted a significant effect on DA release in D2R $-/-$ mice (Fig. 3 ).

To extend these findings we also studied the effects of haloperidol on the release of DA evoked by MFB electrical stimulation. DA release was recorded in anesthetized mice by carbon fiber electrodes implanted either in the striatum or in the AcbSh (Fig. $4 D$ ). We extended the study to the AcbSh because this brain structure is the one expressing the highest concentration of D3 receptors. The AcbSh was studied only by voltammetry because the small extension of this brain region in mice makes it of very difficult access by a microdialysis probe. As previously reported (Dugast et al., 1994; Benoit-Marand et al., 2000), prolonged electrical stimulation of the MFB (10 pulses at $15 \mathrm{~Hz})$ evoked a DA overflow in WT animals, which reached a plateau from the third pulse in striatum (Fig. $4 A$ ) and from the sixth in AcbSh (Fig. $4 B)$. This plateau was attributable to DA reuptake and to autoregulation by D2-like receptors (Suaud-Chagny et al., 1995; Benoit-Marand et al., 2000). Because DA reuptake is slower in nucleus AcbSh than in the striatum (Suaud-Chagny et al., 1995), the plateau was reached later in this structure. When autoreceptor functions were blocked by haloperidol in WT mice, this plateau was not observed (Fig. $4 A, B$ ). Interestingly, after haloperidol injection (Fig. $4 A-C$ ) the maximal amplitude of the evoked DA overflow was enhanced in comparison with the baseline only in WT mice by $+354 \%$ in the striatum and by $+189 \%$ in

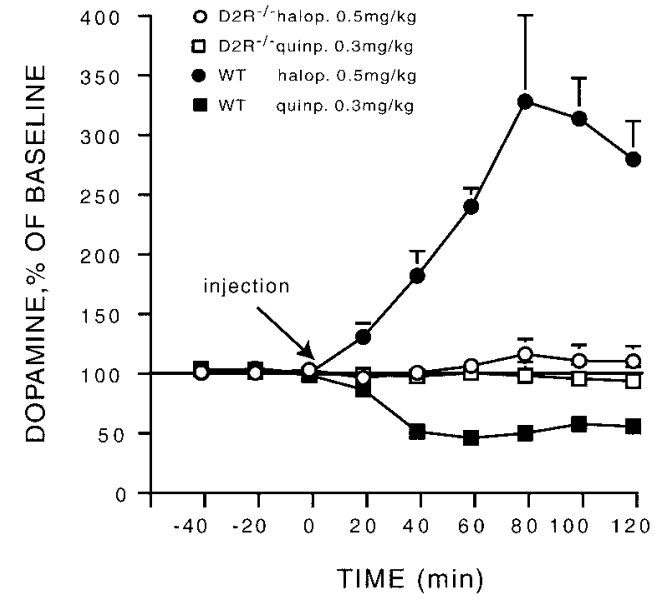

Figure 3. Quinpirole- and haloperidol-induced changes in extracellular concentration of dopamine in WT and D2R-/- mice. The D2-specific agonist (quinpirole) and antagonist (haloperidol) were administered in WT and D2R-/- mice. Quinpirole and haloperidol, respectively, decrease and increased DA release in WT animals. In contrast, the two drugs had no effects in D2R - / - mice. Dialysates were collected in the striatum of freely moving animals every $20 \mathrm{~min}$, and data are expressed as mean \pm SEM of changes from baseline.

AcbSh (ANOVA genotype $\times$ haloperidol interaction, $F_{(1,8)}=$ 83.3, $p<0.0001$ and $F_{(1,8)}=24.0, p<0.002$ in striatum and in AcbSh, respectively). Indeed haloperidol had no significant effect in D2R $-/-$ animals (Fig. $4 A-C$ ) either in striatum or in AcbSh. Importantly, under basal condition, the shape of DA overflow recorded in the striatum and AcbSh of $\mathrm{D} 2 \mathrm{R}-/-$ mice was similar to the one observed in WT animals after haloperidol (no plateau phase) (Fig. 4A,B). It is also larger than the one observed in WT animals before haloperidol (290 and $208 \%$ in striatum and AcbSh, respectively; $p<0.02$ ) (Fig. $4 A, B$ ). These observations show that in WT animals, the DA released by the first pulses stimulated D2 autoreceptors and inhibited the DA release evoked by the last pulses in striatum as well as in AcbSh, although the amplitude of this autoregulation appears more pronounced in the striatum.

\section{Autoinhibition of DA release is suppressed in D2R null mice}

To complete the characterization of autoreceptor function in D2R null mice, we studied the inhibition by endogenous DA of its own release. This phenomenon was studied in the dorsal striatum and in the nucleus AcbSh by applying paired test stimulations (S1 and S2) of the MFB, one of which was preceded by a conditioning stimulation $(\mathrm{Sc})$. The conditioning stimulation (four pulses at 15 $\mathrm{Hz}$ ) used was physiologically relevant and mimicked a burst of action potentials, typically generated by dopaminergic neurons (Grace and Bunney, 1984). The test stimulation (three pulses at $100 \mathrm{~Hz}$ ) was selected as the minimal brief stimulation evoking an accurately measurable DA overflow. In the striatum of WT and $\mathrm{D} 2 \mathrm{R}-/-$ mice, in the absence of conditioning stimulation (no Sc) both test stimulations (S1 and S2) evoked DA overflow of the same maximal amplitude (Fig. $5 A, C$ ). In the dorsal striatum of WT mice, the DA released by the conditioning stimulation inhibited further DA release because the DA overflow evoked by S2 was about half of that evoked by $\mathrm{S} 2$ in the absence of Sc (Fig. $5 A, C)$. In contrast, this autoinhibition was not observed in the dorsal striatum of D2R $-/-$ mice (Fig. $5 A, C)(p>0.1)$ (ANOVA genotype $\times$ Sc interaction, $\left.F_{(1,12)}=41.68 ; p<0.0001\right)$. 


\section{A Striatum}

Baseline

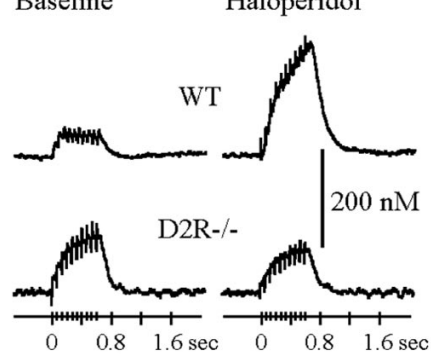

B Accumbens shell

C Effect of haloperidol
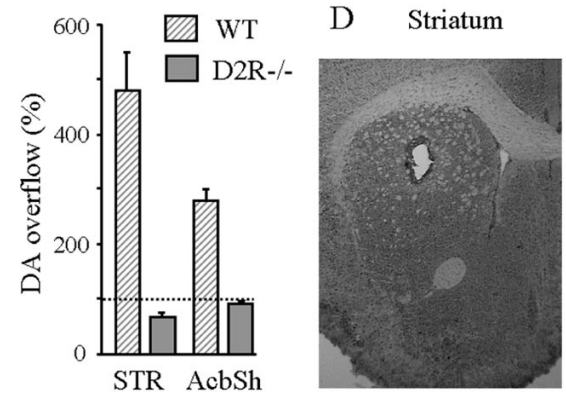

Accumbens shell

Figure 4. Effect of haloperidol on the DA overflow evoked by prolonged stimulations in striatum and AcbSh of WT and D2R $-/-$ mice. Typical recordings of the effect of haloperidol on DA overflow in one WT mouse and one D2R -/- mouse before (Baseline) and $20 \mathrm{~min}$ after haloperidol $(0.5 \mathrm{mg} / \mathrm{kg}$, s.c.). DA overflow was evoked by MFB stimulation consisting of 10 pulses at $15 \mathrm{~Hz}$. The DA overflow recorded in striatum $(A)$ was expressed in terms of changes in DA concentration by in vitro calibration of the electrode. In AcbSh $(B)$, because the carbon fiber electrode was not calibrated after each experiment, the DA overflow was expressed in terms of changes in oxidation current. The maximal amplitude of the DA overflow observed $20 \mathrm{~min}$ after haloperidol was expressed as a percentage of that observed before injection $(C)$. Data are given as mean \pm SEM (5 animals in each group in the striatum, $6 \mathrm{WT}$ and $4 \mathrm{D} 2 \mathrm{R}-/-$ mice in AcbSh). Anatomical location of the electrode tip in the dorsal striatum and accumbens shell $(D)$.

In the AcbSh of WT mice in the absence of conditioning stimulation, S2 evoked a slightly lower DA overflow than that evoked by $\mathrm{S} 1$ (Fig. 5B,C). The DA release evoked by conditioning stimulation ( $\mathrm{Sc}$ ) inhibited further DA release in the AcbSh of WT mice (Fig. $5 B$ ). In contrast, this autoinhibition was not observed in the AcbSh of D2R - /- mice (Fig. 5B,C) $(p=0.13)$ (ANOVA genotype $\times$ Sc interaction, $\left.F_{(1,9)}=38.54 ; p<0.0002\right)$. The autoinhibition induced by Sc in WT mice was higher in striatum than in AcbSh $(p<0.005)$ (Fig. 5C).

\section{DA clearance and DA release per pulse in basal conditions are unaltered in D2R null mice}

To provide a quantitative estimate of DA uptake and a relative estimate of DA release in $\mathrm{D} 2 \mathrm{R}-/-$ mice, DA overflow was evoked by brief MFB electrical stimulations consisting of four pulses at $100 \mathrm{~Hz}$. These conditions were required for a reliable quantification of DA overflow (Garris and Wightman, 1994; Benoit-Marand et al., 2000). The striatal DA half-life was similar in D2R $-/-$ mice and WT littermates (Fig. 6, Table 1) and well correlated to that previously found in C57/B16 mice (BenoitMarand et al., 2000) and rats (Suaud-Chagny et al., 1995). Although the DA half-life recorded from D2R - / - mice was slightly longer in duration as compared with WT siblings, this difference did not reach statistical significance $\left(F_{(1,12)}=3.00 ; p>0.1\right)$. DA clearance depends on DA reuptake, this result suggests that in our experimental conditions there are no major modifications of the DA transporter function in $\mathrm{D} 2 \mathrm{R}-/-$ mice. The maximal amplitudes of the DA overflow evoked by a brief stimulation showed a nonsignificant genotype effect $\left(F_{(1,8)}=3.56 ; p=0.096\right)$ (Fig. 6, Table 1). The evoked DA overflow reflects DA release per pulse (multiplied by the number of pulses) minus DA clearance by reuptake (Garris and Wightman, 1994; Benoit-Marand et al., 2000). Because DA clearance is comparable in WT and D2R-/mice, the similarity of the overflow amplitudes in WT and $\mathrm{D} 2 \mathrm{R}-/-$ mice might be interpreted as a similarity of the DA release per pulse in both genotypes.

\section{Changes in striatal extracellular concentrations of DA in response to cocaine and morphine administration in D2L null mice}

The D2R gene encodes for two independent receptor isoforms, D2L and D2S (Picetti et al., 1997). We have recently shown that deletion of D2L in D2L-/- mice profoundly modifies postsynaptic responses to DA while it preserves autoreceptor-mediated functions (Usiello et al., 2000). These results together with the observed suppression of autoreceptor functions in D2R-/- animals strongly suggest that the D2S is the DA autoreceptor. Consequently, to provide insights into the influence of D2L and $\mathrm{D} 2 \mathrm{~S}$ receptors on the DAergic response to drugs of abuse, we analyzed cocaine and morphine-induced changes in extracellular DA in D2L-/- mice.

Similar DA concentrations were measured in the dialysates from

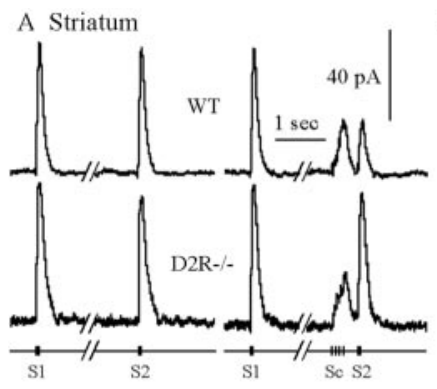

C Striatum

B Accumbens Shell
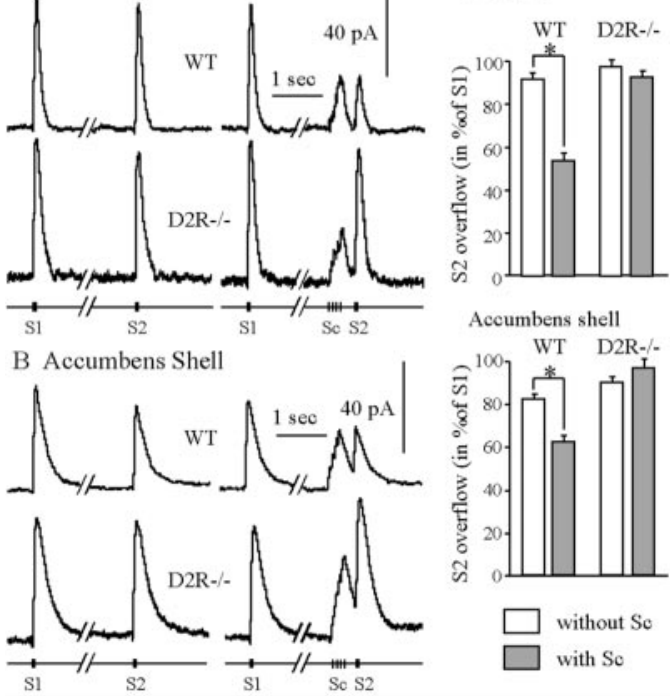

WT D2R--

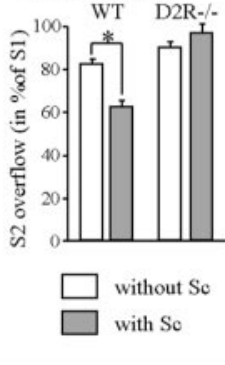

Figure 5. Autoregulation of the evoked DA release in striatum and AcbSh of WT and D2R $-/-$ mice. The DA overflow was evoked in striatum $(A)$ and AcbSh $(B)$ by MFB electrical stimulation. Test stimulations $\mathrm{S} 1$ and $\mathrm{S} 2$ consisted of three pulses at $100 \mathrm{~Hz}$ and were applied 4 sec apart. The conditioning stimulation $(S c)$ consisted of four pulses at 15 $\mathrm{Hz}$, and the delay between the end of Sc and S2 was $300 \mathrm{msec}$. The amplitude of the DA overflow evoked by $\mathrm{S} 2$ was expressed as a percentage of the overflow evoked by $\mathrm{S} 1$ and reflected the inhibition of DA release induced by Sc. The data are given as mean \pm SEM $(8 \mathrm{WT}$ and $6 \mathrm{D} 2 \mathrm{R}-/-$ in striatum, $6 \mathrm{WT}$ and $5 \mathrm{D} 2 \mathrm{R}-/-$ in the shell). In the absence of conditioning stimulation (noSc), S1 and S2 were similar in WT and D2R - / - mice. In WT mice the DA overflow evoked by Sc inhibited DA release evoked by $\mathrm{S} 2\left({ }^{*} p<0.002\right)$. In contrast, in $\mathrm{D} 2 \mathrm{R}-/-$ mice $\mathrm{Sc}$ did not modify further DA release. 


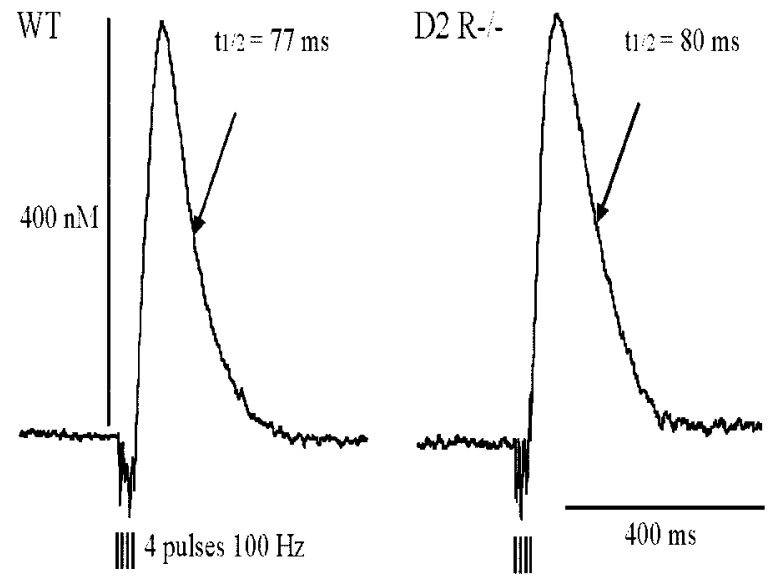

Figure 6. DA overflow evoked in striatum of WT and D2R $-/-$ mice. DA overflow was evoked in the dorsal striatum by MFB electrical stimulation consisting of four pulses at $100 \mathrm{~Hz}$. In each animal the evoked DA overflow was measured with the same electrode at three different depths from the cortical surface $(2.75,3$, and $3.25 \mathrm{~mm})$. DA overflow was expressed in terms of change in dopamine concentration by calibrating the electrode in vitro at the end of each experiment. For each individual overflow two parameters were measured: the half-life (i.e., the time for $50 \%$ decrease from the maximum) and the maximal amplitude. The three pairs of values obtained from the same animal were averaged. Data collected from several experiments are given in Table 1.

WT and D2L $-/-$ animals (WT: $n=13,4.73 \pm 0.6 \mathrm{pg} / 20 \mathrm{~min}$; D2L $-/-: n=12,3.96 \pm 0.37 \mathrm{pg} / 20 \mu \mathrm{l})$ (genotype effect, $F_{(1,23)}=1.12$; $p>0.29)$. The injection of cocaine significantly increased extracellular DA over time $\left(F_{(8,168)}=37.67 ; p<0.0001\right)$ in a dosedependent manner (dose $\times$ time interaction, $F_{(8,168)}=2.71 ; p<$ 0.007) (Fig. 7A). Importantly, cocaine-induced increase in DA levels was identical in the two genotypes (genotype effect, $F_{(1,21)}=$ $0.80 ; p>0.38$ ), regardless of the dose of cocaine used (genotype $\times$ dose interaction, $F_{(1,21)}=0.63 ; p>0.43$ ) or time (genotype $\times$ time interaction, $\left.F_{(5,105)}=0.87 ; p>0.5\right)$.

Morphine administration in WT and D2L mutant mice elicited an increase of the extracellular concentration of DA in the dorsal striatum $\left(F_{(8,104)}=4.05 ; p<0.0003\right)$ in a dose-dependent manner (dose $\times$ time interaction, $\left.F_{(8,104)}=3.88 ; p<0.0004\right)$ (Fig. $7 B$ ). Similarly to what observed for cocaine there was no significant difference in the response to morphine between D2L mutant mice and WT littermates (genotype effect, $F_{(1,13)}=0.56 ; p>0.46$ ) and this regardless of the dose (genotype $\times$ dose interaction, $F_{(1,13)}=$ $0.47 ; p>0.50$ ) used and of time (genotype $\times$ time interaction, $\left.F_{(5,65)}=0.14 ; p>0.97\right)$. Comparison of results in Figures 2 and 7 could be interpreted as the response to morphine, in the WT of $\mathrm{D} 2 \mathrm{R}-/-$ and D2L $-/-$ mice, is different. However, statistical analyses of the values obtained in the two groups did not reveal any significant difference. Furthermore, the only notable difference between means is observed 80 min after morphine administration.
The higher value in the WT of the D2L experiment can be primarily accounted for by one animal that had a very high response as also indicated by the very large error bar at this time point.

These results indicate that a selective deletion of the D2L receptor is not a sufficient condition for increasing the DAergic response to cocaine and morphine, suggesting a critical role of $\mathrm{D} 2 \mathrm{~S}$ in regulating the magnitude of the response to these drugs.

\section{DISCUSSION}

DA plays a key role in the control of various physiological functions. This control is achieved through the interaction with membrane receptors of the D1- or D2-like receptor families. Among these families, members of the D2-like receptors bear an additional important function related to the control of DAergic system homeostasis, the autoreceptor function. The role of autoreceptors is critical, because their activity indirectly regulates the function of all the other DA receptors by modulating DA release. Presynaptic inhibition of DA release is a physiological phenomenon by which extracellular DA stimulates presynaptic autoreceptors to further inhibit DA release. Since 1971 (Farnebo and Hamberger, 1971) this phenomenon has been widely studied in vitro and in vivo (May and Wightman, 1989; Starke et al., 1989; Suaud-Chagny et al., 1991; Wiedemann et al., 1992). In particular, pharmacological as well as anatomical studies have identified D2R and D3R as the potential DA autoreceptors. However, lack of selective ligands able to discriminate between D2 and D3 receptors has led to conflicting results in the establishment of the D2-like receptor controlling the firing, synthesis, and release of DA.

Here, we clearly show that expression of D2R is a necessary condition for the maintenance of presynaptic inhibition. The deletion of D2 receptors in D2R mutant mice suppress the effects of the D2/D3 ligands, quinpirole and haloperidol, on DA release as studied by microdialysis in freely moving animals. These results are further supported by in vivo voltammetry studies performed in the dorsal striatum as well as in the AcbSh, a region where D3 receptors are highly expressed. Using this approach we show that in $\mathrm{D} 2 \mathrm{R}-/-$ mice haloperidol effects on DA release evoked by MFB stimulation were suppressed in both regions. Loss of DA-induced autoinhibition in the dorsal striatum and AcbSh in $\mathrm{D} 2 \mathrm{R}-/-$ mice was also observed using brief MFB stimulation mimicking physiological impulse flow.

Although D2R plays a crucial role in mediating the autoinhibition observed in condition of high extracellular DA concentrations, our results indicate that it plays a moderate role in controlling basal DA release. Indeed, in D2R $-/-$ mice no significant changes were detected in basal extracellular concentrations of DA, as measured by microdialysis (present study; Dickinson et al.,

Table 1. DA release and DA uptake in D2R-/- mice and in WT mice

\begin{tabular}{lll} 
& WT & D2 $-/-$ \\
\hline Half-life (4 pulses, $100 \mathrm{~Hz})$ & $75.2 \pm 3.0 \mathrm{msec}(n=5)$ & $83.2 \pm 3.0 \mathrm{msec}(n=9)$ \\
Amplitude (4 pulses, $100 \mathrm{~Hz})$ & $380 \pm 40 \mathrm{nM}(n=5)$ & $486 \pm 38 \mathrm{nM}(n=6)$
\end{tabular}

Experimental conditions designed to measure the dopamine half-life and the maximal amplitude of the evoked dopamine overflow are shown in Figure 6. The half-life provides a good estimate of dopamine clearance by reuptake. Because DA uptake did not differ in WT and D2R-/- mice, the maximal amplitude of the overflow provides a relative estimate of the dopamine release. Therefore, because this maximal amplitude did not significantly differ between both groups, this shows that dopamine release is very similar in both genotypes. Data are given as mean \pm SEM of $n$ experiments. 


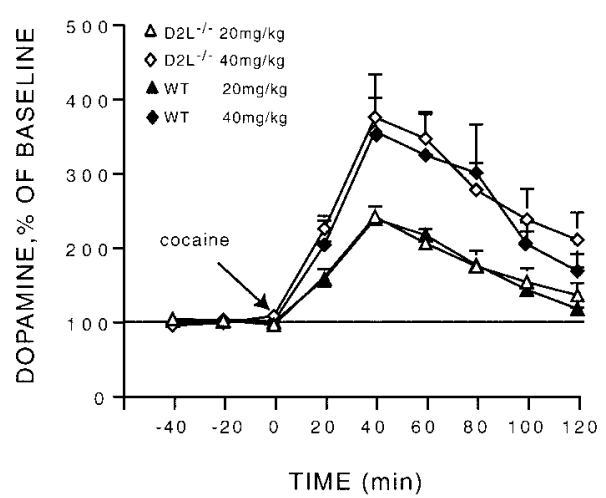

8

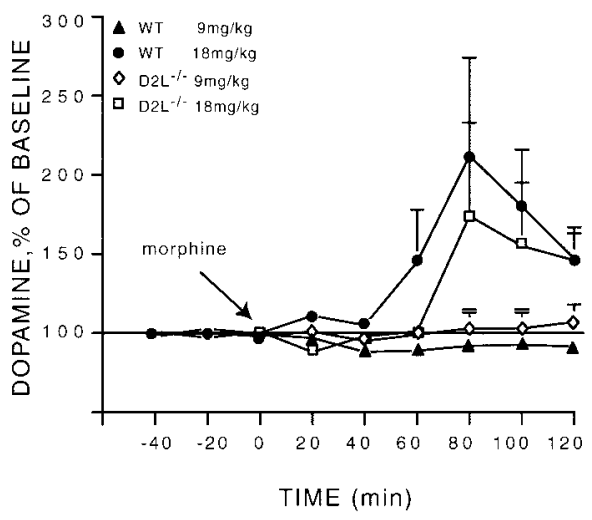

Figure 7. Cocaine and morphine-induced changes in extracellular concentration of dopamine in WT and $\mathrm{D} 2 \mathrm{~L}-/-$ mice. $A$, The administration of cocaine $(20$ and $40 \mathrm{mg} / \mathrm{kg}$, i.p) and morphine $(B)(9$ and $18 \mathrm{mg} / \mathrm{kg}$, s.c.) induced a similar increase in dopamine in D2L $-/-$ and in WT animals. Dialysates were collected in the striatum of freely moving animals every $20 \mathrm{~min}$, and data are expressed as mean \pm SEM of changes from baseline.
1999) or in DA release per pulse by voltammetry. In resting conditions (DA level $10 \mathrm{~nm}$ ), it is very likely that D2R autoreceptors only exerts a moderate tonic inhibition of DA release (SuaudChagny et al., 1991; Dugast et al., 1997). In contrast, a maximal inhibitory autoreceptor activity is observed when DA levels reach concentrations in the range of $100 \mathrm{~nm}$ (Suaud-Chagny et al., 1991).

Previous pharmacological studies had implicated D3R as one of the DA autoreceptors (Devoto et al., 1995; Gobert et al., 1995; Kreiss et al., 1995; Lejeune and Millan, 1995), however results obtained in D3R KO mice did not support these findings. In fact, neither DA synthesis nor the firing rate of dopaminergic neurons is modified in the absence of D3R (Koeltzow et al., 1998). Furthermore, putative selective D3R agents were able to elicit similar effects in D3R-KO and WT mice (Koeltzow et al., 1998). This suggests that the autoreceptor effects originally attributed to the D3R in those studies where actually mediated by D2Rs. Conversely, ablation of D2R expression leads to a total abrogation of the inhibitory effects of DA on the firing of DAergic neurons in the substantia nigra (Mercuri et al., 1997). In addition, analysis of striatal synaptosomes preparations from D2R-/mice also suggested a primary role of D2R in the control of DA release (L'Hirondel et al., 1998). These observations together with the results presented in this article indicate that D2R is the major DA autoreceptor. Nevertheless, the study of Koeltzow et al. (1998) has shown that DA basal efflux is significantly higher in D3R - / - mice with respect to WT littermates. We did not observe such a difference between D2R - / - mice and WT controls. This raises the interesting possibility that D3R is not directly involved in the regulation of DA release from DAergic neurons, a function that is served by D2R, but they could control basal DA levels. It has indeed been postulated that D3R activity would mediate a postsynaptic inhibitory feedback, which in its absence would increase basal DA efflux (Koeltzow et al., 1998). These findings together with ours may finally assign a role to D2R and $\mathrm{D} 3 \mathrm{R}$ in regulating DA release.

It has been previously shown that D2R can modulate DA uptake (Meiergerd et al., 1993; Cass and Gerhardt, 1994) and that DA uptake is decreased in mice lacking D2 receptors (Dickinson et al., 1999). Here we observed a trend to a lower DA half-life in D2R - / - mice compared with WT that was not statistically significant. Because this parameter is almost entirely governed by DA reuptake (Suaud-Chagny et al., 1995; Benoit-Marand et al., 2000), at first glance, the present results seem inconsistent with previous studies (Meiergerd et al., 1993; Cass and Gerhardt,
1994; Dickinson et al., 1999). However, the DA overflow used here to measure DA half-life was evoked by brief MFB stimulation, which reached a maximal amplitude at $<0.5 \mu \mathrm{M}$. In contrast, Meiergerd et al. (1993) estimated the DA clearance rate from DA overflows, evoked by local injection of high $\mathrm{K}^{+}$concentration, reaching a maximal amplitude exceeding $25 \mu \mathrm{M}$. In both other studies (Cass and Gerhardt, 1994; Dickinson et al., 1999), exogenous DA was locally applied at a concentration of 200-400 $\mu \mathrm{M}$, the resulting DA overflow was measured at $0.3 \mathrm{~mm}$ from the injection pipette and reached a maximal amplitude exceeding 1 $\mu \mathrm{M}$. Altogether these observations suggest that DA uptake is minimally regulated by $\mathrm{D} 2$ receptors in resting conditions, like in our experiments in which a not statistically significant trend was found, but play a significant role in case of high extracellular DA levels, like in previous published reports, in which the DA transporters work closer to saturation and in which D2 receptors are strongly stimulated.

The observation that D2R-mediated autoinhibition plays a major role in controlling DA release in conditions of high extracellular DA levels might explain the large influence of D2R on changes in extracellular DA induced by drugs of abuse. Thus, the increase in DA induced by drug of abuse is among the highest measurable and well above those induced by physiological stimuli. Interestingly, our results show that DA increase in response to morphine and cocaine is different in $\mathrm{D} 2 \mathrm{R}-/-$ mice and is greater in response to cocaine than to morphine. This is very likely attributable to the different mechanisms of action of the two drugs. Cocaine increases DA by blocking the reuptake (Povlock and Schenk, 1997). Thus, in normal conditions the autoreceptor, which inhibits firing and DA release, is the only remaining factor able to counteract cocaine effect. Indeed, in the absence of autoreceptors (i.e., D2R-/- mice), an extremely high increase of DA is observed. In contrast, morphine acts by increasing the firing of dopaminergic neurons (Johnson and North, 1992). Consequently, loss of autoreceptors should lower the threshold of morphine effect. However, the limiting factor in this case is the activity of the DAT. Thus, when morphine is administered DA increase should be, at least partially, compensated by DAT activity even in the absence of the autoreceptors. Our results are in line with this hypothesis. D2R - / - mice do present a lower threshold response to morphine than WT littermates. The difference between the two groups at high morphine doses is still significant, but reduced in comparison to the one observed with cocaine. Furthermore, a clear difference between D2R $-/-$ and WT appears only late in time. This suggests that at the beginning 
of the response to morphine DAT is the principal factor limiting DA release and that inhibition of firing by autoreceptors plays an essential role only when DA levels are high enough to significantly stimulate D2 receptors.

Importantly, we show that the selective ablation of the D2L isoform of the D2R does not modify the extracellular levels of DA in response to cocaine and morphine. These results suggest that D2S receptors, which are still expressed in D2L-/- mice, play a crucial role in the regulation of drug-induced changes in DA. Consequently, the large enhancement of extracellular DA, induced by cocaine and morphine in $\mathrm{D} 2 \mathrm{R}-/-$ mice, appears very likely to be caused by the deletion of the D2S isoform of the D2 receptor. These are probably the most relevant results shown in this study, because an increase in DA release has been shown to be a key event mediating the addictive effect of drugs of abuse. Therefore, we might speculate that a deregulation of D2 autoreceptor function, and in particular of the D2S isoform, might play an important role in the pathophysiology of drug abuse as well as in mediating vulnerability to drugs. This hypothesis is indirectly supported by observations in animals spontaneously vulnerable to drug abuse (Piazza et al., 1989; Piazza and Le Moal, 1996). These animals are characterized by an enhanced release of DA in response to addictive drugs (Hooks et al., 1991; Rouge-Pont et al., 1993) as well as by a lower number of D2R binding sites (Hooks et al., 1994) and lower inhibition of DA discharge activity resulting from reduced somatodendritic autoreceptor sensitivity (Marinelli and White, 2000).

In conclusion, D2Rs and in particular the D2S isoform are key elements in regulating DA increase induced by drugs of abuse. The present findings strengthen the hypothesis that deregulation of the expression of these receptors, by increasing the DAergic response to drugs of abuse, play a crucial role in the pathophysiology of addiction.

\section{REFERENCES}

Baik JH, Picetti R, Saiardi A, Thiriet G, Dierich A, Depaulis A, Le Meur M, Borrelli E (1995) Parkinsonian-like locomotor impairment in mice lacking dopamine D2 receptors. Nature 377:424-428.

Benoit-Marand M, Jaber M, Gonon F (2000) Release and elimination of dopamine in vivo in mice lacking the dopamine transporter: functional consequences. Eur J Neurosci 12:2985-2992.

Berke JD, Hyman SE (2000) Addiction, dopamine, and the molecular mechanisms of memory. Neuron 25:515-532.

Cass WA, Gerhardt GA (1994) Direct in vivo evidence that D2 dopamine receptors can modulate dopamine uptake. Neurosci Lett 176:259-263.

Devoto P, Collu M, Muntoni AL, Pistis M, Serra G, Gessa GL, Diana M (1995) Biochemical and electrophysiological effects of 7-OH-DPAT on the mesolimbic dopaminergic system. Synapse 20:153-155.

Di Chiara G (1995) The role of dopamine in drug abuse viewed from the perspective of its role in motivation. Drug Alcohol Depend 38:95-137.

Diaz J, Pilon C, Le Foll B, Gros C, Triller A, Schwartz JC, Sokoloff P (2000) Dopamine D3 receptors expressed by all mesencephalic dopamine neurons. J Neurosci 20:8677-8684.

Dickinson SD, Sabeti J, Larson GA, Giardina K, Rubinstein M, Kelly MA, Grandy DK, Low MJ, Gerhardt GA, Zahniser NR (1999) Dopamine D2 receptor-deficient mice exhibit decreased dopamine transporter function but no changes in dopamine release in dorsal striatum. J Neurochem 72:148-156.

Dugast C, Suaud-Chagny MF, Gonon F (1994) Continuous in vivo monitoring of evoked dopamine release in the rat nucleus accumbens by amperometry. Neuroscience 62:647-654.

Dugast C, Brun P, Sotty F, Renaud B, Suaud-Chagny MF (1997) On the involvement of a tonic dopamine D2-autoinhibition in the regulation of pulse-to-pulse-evoked dopamine release in the rat striatum in vivo. Naunyn Schmiedebergs Arch Pharmacol 355:716-719.

Farnebo LO, Hamberger B (1971) Drug-induced changes in the release of $3 \mathrm{H}$-monoamines from field stimulated rat brain slices. Acta Physiol Scand [Suppl] 371:35-44.

Franklin K, Paxinos G (1997) The mouse brain in stereotaxic coordinates. San Diego: Academic.
Garris PA, Wightman RM (1994) In vivo voltammetric measurement of evoked extracellular dopamine in the rat basolateral amygdaloid nucleus. J Physiol (Lond) 478:239-249.

Giros B, Jaber M, Jones SR, Wightman RM, Caron MG (1996) Hyperlocomotion and indifference to cocaine and amphetamine in mice lacking the dopamine transporter. Nature 379:606-612.

Gobert A, Rivet JM, Audinot V, Cistarelli L, Spedding M, Vian J, Peglion JL, Millan MJ (1995) Functional correlates of dopamine D3 receptor activation in the rat in vivo and their modulation by the selective antagonist, (+)-S 14297: II. Both D2 and "silent" D3 autoreceptors control synthesis and release in mesolimbic, mesocortical and nigrostriatal pathways. J Pharmacol Exp Ther 275:899-913.

Grace AA, Bunney BS (1984) The control of firing pattern in nigral dopamine neurons: burst firing. J Neurosci 4:2877-2890.

Graefe RA, Bonish H (1988) The transport of amines across the axonal membranes of noradrenergic and dopaminergic neurones, Vol 90, Handbook of experimental pharmacology (Trendelenburg $U$ and Weiner N, eds), pp 193-245. Berlin: Springer.

Hooks MS, Jones GH, Smith AD, Neill DB, Justice JB (1991) Response to novelty predicts the locomotor and nucleus accumbens dopamine response to cocaine. Synapse 9:121-128.

Hooks MS, Juncos JL, Justice JB, Meiergerd SM, Povlock SL, Schenk JO, Kalivas PW (1994) Individual locomotor response to novelty predicts selective alterations in D1 and D2 receptors and mRNAs. J Neurosci 14:6144-6152.

Jackson DM, Westlind-Danielsson A (1994) Dopamine receptors: molecular biology, biochemistry and behavioural aspects. Pharmacol Ther 64:291-370.

Johnson SW, North RA (1992) Opioids excite dopamine neurons by hyperpolarization of local interneurons. J Neurosci 12:483-488.

Koeltzow TE, Xu M, Cooper DC, Hu XT, Tonegawa S, Wolf ME, White FJ (1998) Alterations in dopamine release but not dopamine autoreceptor function in dopamine D3 receptor mutant mice. J Neurosci 18:2231-2238.

Kreiss DS, Bergstrom DA, Gonzalez AM, Huang KX, Sibley DR, Walters JR (1995) Dopamine receptor agonist potencies for inhibition of cell firing correlate with dopamine D3 receptor binding affinities. Eur J Pharmacol 277:209-214.

L'Hirondel M, Cheramy A, Godeheu G, Artaud F, Saiardi A, Borrelli E, Glowinski J (1998) Lack of autoreceptor-mediated inhibitory control of dopamine release in striatal synaptosomes of D2 receptor-deficient mice. Brain Res 792:253-262.

Lejeune F, Millan MJ (1995) Activation of dopamine D3 autoreceptors inhibits firing of ventral tegmental dopaminergic neurones in vivo. Eur J Pharmacol 275:R7-9.

Marinelli M, White FJ (2000) Enhanced vulnerability to cocaine selfadministration is associated with elevated impulse activity of midbrain dopamine neurons. J Neurosci 20:8876-8885.

May LJ, Wightman RM (1989) Effects of D-2 antagonists on frequencydependent stimulated dopamine overflow in nucleus accumbens and caudate-putamen. J Neurochem 53:898-906.

Meiergerd SM, Patterson TA, Schenk JO (1993) D2 receptors may modulate the function of the striatal transporter for dopamine: kinetic evidence from studies in vitro and in vivo. J Neurochem 61:764-767.

Mercuri NB, Saiardi A, Bonci A, Picetti R, Calabresi P, Bernardi G, Borrelli E (1997) Loss of autoreceptor function in dopaminergic neurons from dopamine D2 receptor deficient mice. Neuroscience 79:323-327

Michael DJ, Wightman RM (1999) Electrochemical monitoring of biogenic amine neurotransmission in real time. J Pharmacol Biomed Anal 19:33-46.

Piazza PV, Le Moal ML (1996) Pathophysiological basis of vulnerability to drug abuse: role of an interaction between stress, glucocorticoids, and dopaminergic neurons. Annu Rev Pharmacol Toxicol 36:359-378,

Piazza PV, Le Moal M (1998) The role of stress in drug selfadministration. Trends Pharmacol Sci 19:67-74.

Piazza PV, Deminiere JM, Le Moal M, Simon H (1989) Factors that predict individual vulnerability to amphetamine self- administration. Science 245:1511-1513.

Picetti R, Saiardi A, Abdel Samad T, Bozzi Y, Baik JH, Borrelli E (1997) Dopamine D2 receptors in signal transduction and behavior. Crit Rev Neurobiol 11:121-142.

Povlock SL, Schenk JO (1997) A multisubstrate kinetic mechanism of dopamine transport in the nucleus accumbens and its inhibition by cocaine. J Neurochem 69:1093-1105.

Roth RH (1984) CNS dopamine autoreceptors: distribution, pharmacology, and function. Ann NY Acad Sci 430:27-53.

Rouge-Pont F, Piazza PV, Kharouby M, Le Moal M, Simon H (1993) Higher and longer stress-induced increase in dopamine concentrations in the nucleus accumbens of animals predisposed to amphetamine self- administration. A microdialysis study. Brain Res 602:169-174

Seeman P, Kapur S (2000) Schizophrenia: more dopamine, more D2 receptors. Proc Natl Acad Sci USA 97:7673-7675. 
Shafer RA, Levant B (1998) The D3 dopamine receptor in cellular and organismal function. Psychopharmacology (Berl) 135:1-16.

Sora I, Wichems C, Takahashi N, Li XF, Zeng Z, Revay R, Lesch KP, Murphy DL, Uhl GR (1998) Cocaine reward models: conditioned place preference can be established in dopamine- and in serotonintransporter knockout mice. Proc Natl Acad Sci USA 95:7699-7704.

Starke K, Gothert M, Kilbinger H (1989) Modulation of neurotransmitter release by presynaptic autoreceptors. Physiol Rev 69:864-989.

Suaud-Chagny MF, Ponec J, Gonon F (1991) Presynaptic autoinhibition of the electrically evoked dopamine release studied in the rat olfactory tubercle by in vivo electrochemistry. Neuroscience 45:641-652.

Suaud-Chagny MF, Dugast C, Chergui K, Msghina M, Gonon F (1995)
Uptake of dopamine released by impulse flow in the rat mesolimbic and striatal systems in vivo. J Neurochem 65:2603-2611.

Usiello A, Baik JH, Rouge-Pont F, Picetti R, Dierich A, LeMeur M, Piazza PV, Borrelli E (2000) Distinct functions of the two isoforms of dopamine D2 receptors. Nature 408:199-203.

White FJ, Kalivas PW (1998) Neuroadaptation involved in amphetamine and cocaine addiction. Drug Alcohol Depend 51:141-153.

Wiedemann DJ, Garris PA, Near JA, Wightman RM (1992) Effect of chronic haloperidol treatment on stimulated synaptic overflow of dopamine in the rat striatum. J Pharmacol Exp Ther 261:574-579.

Wise RA (1996) Neurobiology of addiction. Curr Opin Neurobiol 6:243-251. 